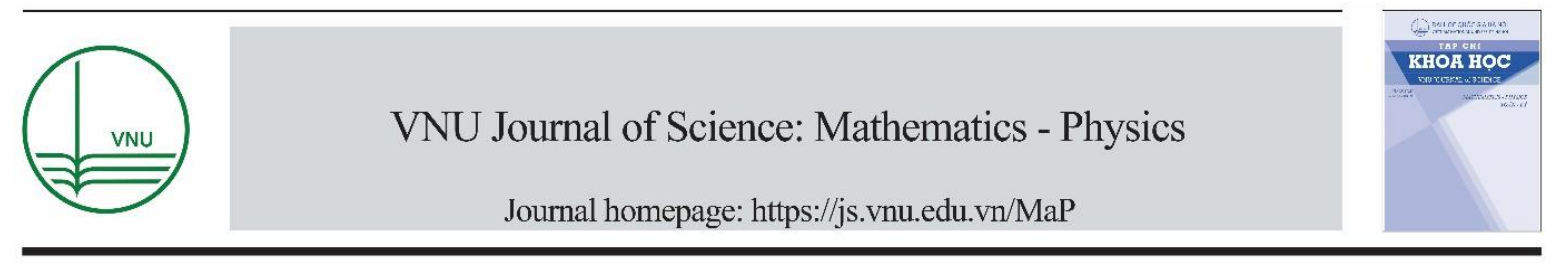

Original Article

\title{
Synthesis and Optical Characterizations of the Fluorescence Silica Nanoparticles Containing Quantum Dots
}

\author{
Chu Viet $\mathrm{Ha}^{1}$, Chu Anh Tuan ${ }^{2}$, Nguyen Thi Bich Ngoc ${ }^{3}$, \\ Tran Hong Nhung 3 , Nguyen Quang Liem ${ }^{4}$, Vu Thi Kim Lien ${ }^{5,6}$ \\ ${ }^{1}$ Thai Nguyen University of Education, 20 Luong Ngoc Quyen, Thai Nguyen, Vietnam \\ ${ }^{2}$ Vietnam University of Traditional Medicine, 2 Tran Phu, Ha Dong, Hanoi, Vietnam \\ ${ }^{3}$ Institute of Physics, Vietnam Academy of Science and Technology, 18 Hoang Quoc Viet, Ha Noi, Vietnam \\ ${ }^{4}$ Institute of Materials Science, VAST, 18 Hoang Quoc Viet, Hanoi, Vietnam \\ ${ }^{5}$ Institute of Theoretical and Applied Research, Duy Tan University, 1 Phung Chi Kien, Hanoi, Vietnam \\ ${ }^{6}$ Faculty of Natural Sciences, Duy Tan University, Da Nang, 550000, Vietnam - 3 Quang Trung, Da Nang, Vietnam
}

Received 03 March 2020

Revised 14 April 2020; Accepted 16 April 2020

\begin{abstract}
The quantum dots coated by silica is fluorescence material class with great biocompatibility, low toxicity and water-solubility, that is suitable for bioapplications. This work presents the synthesis of $\mathrm{SiO}_{2}$ coated $\mathrm{CdTe} / \mathrm{ZnSe}$ (named CdTe) quantum dots $\left(\mathrm{CdTe} @ \mathrm{SiO}_{2}\right.$ nanoparticles) via a wet chemmical route called modified Stöber method. The compounds tetraethylorthosilicate (TEOS) has used as precursors, aminopropyltriethoxysilane (APTES) is as electric neutralizer, and ammonium hydroxide is used as catalysts. The size of $\mathrm{CdTe} @ \mathrm{SiO}_{2}$ nanoparticles was estimated about 70 to $150 \mathrm{~nm}$ depending on the quantities of $\mathrm{H}_{2} \mathrm{O}$, APTEOS, and catalysts. The emission behaviours of $\mathrm{SiO}_{2}$ coated quantum dots was effected by ratio of substances participating in the reaction and synthesis conditions. with the ratio (by volume) of suitable substances: TEOS:solution of QDs: $\mathrm{NH}_{4} \mathrm{OH}$ :APTES: $\mathrm{H}_{2} \mathrm{O}$ being $1.5: 1.5 \times 10^{-2}: 0.8 \times 10^{-2}: 4 \times 10^{-2}: 3 \times 10^{-4}: 5 \times 10^{-2}$, the prepared silica nanoparticles containing quantum dots show high fluorescence emission efficiency, with the fluorescence intensity is higher than that of uncoated CdTe/ZnSe quantum dots. This is a positive result in the technique of manufacturing luminescent silica nanoparticles containing quantum dots. The results show an ability to use the $\mathrm{CdTe} @ \mathrm{SiO}_{2}$ nanoparticles for biological application.
\end{abstract}

Keywords: Stöber method, fluorescence $\mathrm{SiO}_{2}$ nanoparticles, CdTe quantum dots, aminopropyltriethoxysilane precursor, ammonium hydroxide catalysts.

\section{Introduction}

Nowadays, quantum dots have emerged as a new class of fluorescent probes for in vivo biomolecular and cellular imaging because they are highly photo-stable with broad absorption spectra, narrow size-

\footnotetext{
${ }^{*}$ Corresponding author.

Email address: vutkimlien@duytan.edu.vn
}

https//doi.org/ 10.25073/2588-1124/vnumap.4476 
tunable emission spectra covering from ultraviolet (UV) to infrared (IR) region. They have long fluorescence lifetimes and remarkably resistant to photobleaching [1-8].

Despite numerous such advantages due to the exhibition of high-quality fluorescence, it would be difficult to use quantum dots in biomedical applications because of several drawbacks including high toxicity, low dispersion in water or biological environments, and fluorescence blinking. These problems can be solved by creating intermediate layers or coating the shells around the quantum dots. The core/shell structure supports quantum dots have longer-term optical stability and higher quantum yield. Silica is one of the optimal options to problems of quantum dots. When surrounded by chemically inert silica shells, quantum dots could be prevented from the effects of the environment on the optical properties. Furthermore, silica nanoparticles not only were non-toxic and transparent for visible light regions, but they can be well dispersed in biological environments, have high biological compatibility, and are easy to bind with biological entities [9-12]; However, they did not discuss about changing emission properties of $\mathrm{SiO}_{2}$ coated quantum dots due to different reaction conditions. There are several chemical routes known for the synthesis of silica nanoparticles in solution. But the most common approach is Stöber method which has involved grafting of organic groups by chemical reaction of presynthesized silica particles with certain coupling agents $[13,14]$. This simple method can be carried out with non toxic solvents such as water or ethanol, and has been modified to incorporate quantum dots inside the silica nanoparticles and reform high uniform beads. However, these techniques face a common problem that the fluorescent efficiency of the sample is significantly reduced [15-21]. Although there were some work have done to improve the manufacturing process, the fluorescence efficiency of quantum dots after silica coating still decreases. This degeneration is probably related to surface traps formed during silica formation [18]; due to TEOS hydrolysis [20], the influence of ammonia catalysts, or exchange the ligands of silane precursors can damage the surface of the quantum dots [16]. For this reason, the researches in order to prevent this decline are essential.

Several researches of preparing single quantum dot in a silica sphere were published. Thomas Nann and coworkers have synthezied silica coated quantum dots by using oil-in-water microemulsion system with cyclohexane as the "oil" phase and Synperonic NP-5 as the surfactant [22]. Xingguang Su et al, Yunhua Yang and Mingyan Gao who were successful in synthesis of aqueous CdTe quantum dots embedded silica nanoparticles by reverse micelle method [21, 23, 24]. They inserted many quantum dots in each silica particle using PDDA (polydimethyldiallyl ammonium chloride) to balance the electrostatic repulsion between CdTe quantum dots and silica intermediates. Although this method created high quality silica nanoparticles, however, it used toxic solution effect on healthy of researcher and environment. In comparison with reverse micelle method, Stöber method used a nontoxic solvent, ethanol, as reaction media. Thomas Nann and Paul Muvanlney created single silica coated single quantum dot by using TEOS to colloidal stable seed particles in an $\mathrm{EtOH} / \mathrm{H}_{2} \mathrm{O} / \mathrm{NH}_{3}$ mixtures [22]. Yoshio Kobayashi et al used $\mathrm{NaOH}$ in their Stöber method. They presented effect concentration of TEOS and concentration of $\mathrm{NaOH}$ on formation process of silica shell and properties of $\mathrm{SiO}_{2}$ coated quantum dots $[25,26,27]$, but they have no discussion about changing emission properties of $\mathrm{SiO}_{2}$ coated quantum dots due to different reaction conditions.

In this work, the $\mathrm{CdTe} / \mathrm{ZnS}$ quantum dots are coated by a silica layer in ethanol solvent via Stöber method using ammonium hydroxide $\left(\mathrm{NH}_{4} \mathrm{OH}\right)$ as catalysts. Effect of reaction substances (TEOS, $\mathrm{NH}_{4} \mathrm{OH}$, APTES and water) ratios on the perform of $\mathrm{CdTe} @ \mathrm{SiO}_{2}$ nanoparticles and their optical propeties were investigated. The size of $\mathrm{CdTe} @ \mathrm{SiO}_{2}$ nanoparticles was estimated about 70 to $150 \mathrm{~nm}$. The emission behaviours of $\mathrm{SiO}_{2}$ coated quantum dots was effected by ratios of substances participating in the Several researches of preparing single quantum dot in a silica sphere were published. Thomas Nann and coworkers have synthezied silica coated quantum dots by using oil-in-water microemulsion system with 
cyclohexane as the "oil" phase reaction and synthesis conditions. In our work, with a solution volume of $\mathrm{CdTe} / \mathrm{ZnSe}$ quantum dots of $80 \mu \mathrm{l}$ (containing about $10^{15}$ quantum dot particles $/ \mathrm{mL}$ ), the proportion (by volume) of suitable substances was obtained. With this ratio, the silica nanoparticles containing quantum dots have exhibited a high fluorescence emission efficiency, the fluorescence intensity is higher than that of uncoated $\mathrm{CdTe} / \mathrm{ZnSe}$ quantum dots. This is a positive result in the technique of manufacturing luminescent silica nanoparticles containing quantum dots. The results show an ability to use the $\mathrm{CdTe} @ \mathrm{SiO}_{2}$ nanoparticles for biological application.

\section{Experiments}

The CdTe/ZnS quantum dots were synthesized as-prepared in [8] with 4-5 $\mathrm{nm}$ in size. For synthesis of fluorescence $\mathrm{SiO}_{2}$ nanoparticles with CdTe quantum dots via Stöber method, tetraethylorthosilicate (TEOS, Sigma Aldrich) were used as precursors, $\mathrm{NH}_{4} \mathrm{OH}$ (Sigma Aldrich) was used as catalyst in sol gel process. Due to the negatively charged $\mathrm{CdTe} / \mathrm{ZnS}$ quantum dot surface (because of presence of the carboxyl COO- group) and the silica network formed through hydrolysis and condensation processes is also negatively charged [27], APTES $\left(\mathrm{C}_{9} \mathrm{H}_{23} \mathrm{NO}_{3} \mathrm{Si}\right)$ was used as electric neutralizer for easly growing of $\mathrm{SiO}_{2}$ shell on the quantum dots face. Ethanol (Merck) and purified water from Millipore were used in the synthesis. The synthesis route of fluorescence $\mathrm{SiO}_{2}$ nanoparticles with $\mathrm{CdTe}$ quantum dots by modified Stöber method is described in figure 1. The mixture of CdTe quantum dots and APTES was ultrasonic vibrated in ethanol and then was added in the ethanol solution containing TEOS magnetic stirred before. After that, the ammonium hydroxide catalyst was added in the solution to create the reaction to form silica particles containing the quantum dots inside. The solution was magnetic stirred for 24 hours. The silica-coated quantum dots $\left(\mathrm{CdTe} @ \mathrm{SiO}_{2}\right)$ nanoparticles samples then have been cleaned by centrifugation in ethanol.

Based on the equations of hydrolysis and condensation reaction, we chose fix amounts of ethanol solvent and TEOS precursor are chosed of $15 \mathrm{ml}$ and $150 \mu \mathrm{l}$; amount of solution containing CdTe /ZnS quantum dots is $80 \mu \mathrm{l}$ (with a concentration of about $10^{15}$ particles $/ \mathrm{mL}$ ). The amount of other substances is changed to investigate their effect on the emission of quantum dots. The amounts of substances are given in tables 1,2 and 3 .

The size and shape of $\mathrm{CdTe} @ \mathrm{SiO}_{2}$ nanoparticles were determined by transmission electron microscopes (TEM, JEM 1011). Absorption spectra were measured using JASCO-V570-UV-Vis-NIR spectrometer. The fluorescence spectra were recorded on a Cary Eclipse spectrofluorometer (Varian).

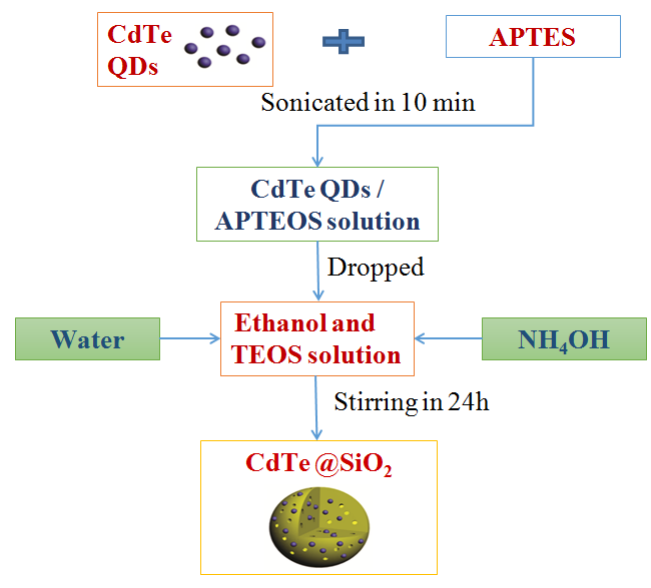

Fig.1. Diagram of synthesis CdTe@ $\mathrm{SiO}_{2}$ nanoparticles via Stöber method. 


\section{Results and Discussion}

The CdTe@ $\mathrm{SiO}_{2}$ nanoparticles were synthesized as colloidal particles dispersed in aqueous or ethanol solutions. The solution of prepared nanoparticles samples is opaque white, that is color of silica. Figure 2 presents the TEM image of one sample of $\mathrm{CdTe} @ \mathrm{SiO}_{2}$ nanoparticles. It shows that the particle shape is spherical with the average diameter of about $110 \mathrm{~nm}$ with high monodispersion. The results show the success of synthesis $\mathrm{SiO}_{2}$ nanoparticles containing $\mathrm{CdTe} / \mathrm{ZnS}$ quantum dots. The size of silica nanoparticles vary from 70 to $150 \mathrm{~nm}$ depending on the concentration of reactants and the catalyst of the synthesis.

Table 1. Amounts of substances for survey by amount change of APTES

\begin{tabular}{|l|l|l|l|l|l|}
\hline Ethanol $(\mathrm{ml})$ & TEOS $(\mu \mathrm{l})$ & QDs CdTe $(\mu \mathrm{l})$ & $\mathrm{NH}_{4} \mathrm{OH}(\mu \mathrm{l})$ & APTES $(\mu \mathrm{l})$ & $\mathrm{H}_{2} \mathrm{O}(\mu \mathrm{l})$ \\
\hline 15 & 150 & 80 & 400 & 0 & 700 \\
15 & 150 & 80 & 400 & 1.5 & 700 \\
15 & 150 & 80 & 400 & 3 & 700 \\
15 & 150 & 80 & 400 & 4.5 & 700 \\
\hline
\end{tabular}

Table 2. Amounts of substances for survey by amount change of $\mathrm{NH}_{4} \mathrm{OH}$

\begin{tabular}{|l|l|l|l|l|l|}
\hline Ethanol $(\mathrm{ml})$ & TEOS $(\mu \mathrm{l})$ & QDs CdTe $(\mu \mathrm{l})$ & $\mathrm{NH}_{4} \mathrm{OH}(\mu \mathrm{l})$ & APTES $(\mu \mathrm{l})$ & $\mathrm{H}_{2} \mathrm{O}(\mu \mathrm{l})$ \\
\hline 15 & 150 & 80 & 200 & 3 & 700 \\
15 & 150 & 80 & 400 & 3 & 700 \\
15 & 150 & 80 & 600 & 3 & 700 \\
15 & 150 & 80 & 800 & 3 & 700 \\
\hline
\end{tabular}

Table 3. Amounts of substances for survey by amount change of $\mathrm{H}_{2} \mathrm{O}$

\begin{tabular}{|l|l|l|l|l|l|}
\hline Ethanol $(\mathrm{ml})$ & TEOS $(\mu \mathrm{l})$ & QDs CdTe $(\mu \mathrm{l})$ & $\mathrm{NH}_{4} \mathrm{OH}(\mu \mathrm{l})$ & APTES $(\mu \mathrm{l})$ & $\mathrm{H}_{2} \mathrm{O}(\mu \mathrm{l})$ \\
\hline 15 & 150 & 80 & 400 & 3 & 300 \\
15 & 150 & 80 & 400 & 3 & 500 \\
15 & 150 & 80 & 400 & 3 & 700 \\
15 & 150 & 80 & 400 & 3 & 900 \\
\hline
\end{tabular}

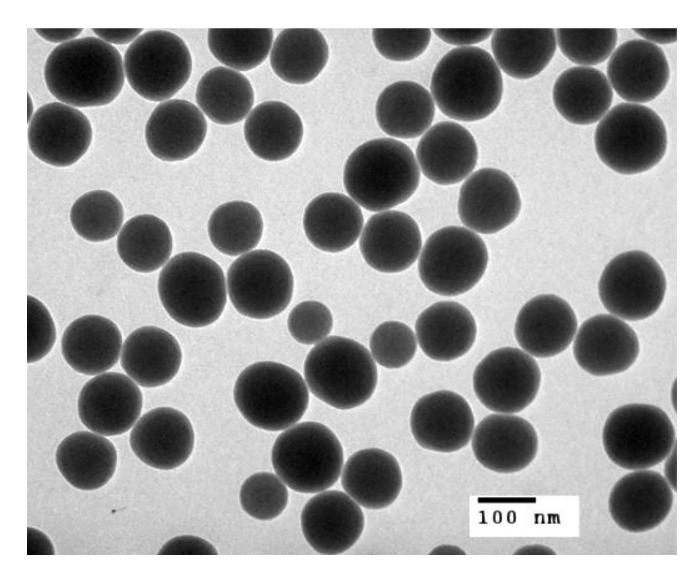

Fig.2. TEM image of CdTe@ $\mathrm{SiO}_{2}$ nanoparticles. 
The measurement of absorption spectra in UV - VIS region of the CdTe quantum dots and $\mathrm{CdTe} @ \mathrm{SiO}_{2}$ nanoparticles was performed at room temperature. Figure $3 \mathrm{~A}$ và $3 \mathrm{~B}$ presents the absorption spectra of CdTe quantum dots and $\mathrm{CdTe} @ \mathrm{SiO}_{2}$ nanoparticles with the same concentration of CdTe quantum dots. The absorption spectrum of $\mathrm{CdTe} @ \mathrm{SiO}_{2}$ nanoparticles is a sloping line that has not absorption peak in comparation with that of CdTe quantum dots. This can be explained that due to the interaction between CdTe quantum dots and host silica matrix, and the distribution of quantum dots in one silica particle is inhomogeneous; the absorption peak of $\mathrm{CdTe} @ \mathrm{SiO}_{2}$ nanoparticles cannot be observed. The absorbance of $\mathrm{CdTe} @ \mathrm{SiO}_{2}$ nanoparticles is higher than that of CdTe quantum dots due to the contribution of absorption of silica matrix.

The results in our work show that, coating silica shell hardly affects on emission wavelength from CdTe quantum dots. The shape of fluorescence spectra of $\mathrm{CdTe} @ \mathrm{SiO}_{2}$ nanoparticles is similar to that of uncoated CdTe quantum dots. However, ratios of substances participating in the reaction have significant influence on perform of $\mathrm{CdTe} @ \mathrm{SiO}_{2}$ nanoparticles and their fluorescent intensities.

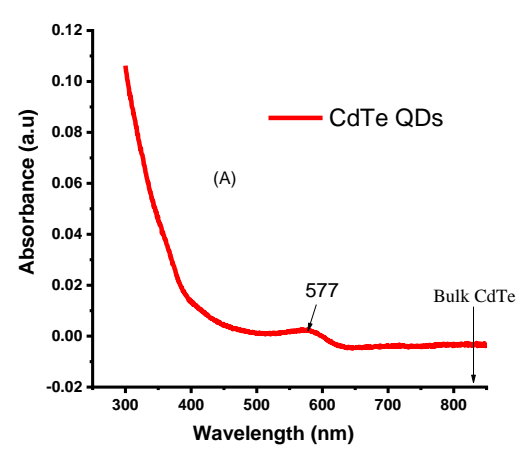

Fig.3A. Absorption spectrum of CdTe quantum dots.

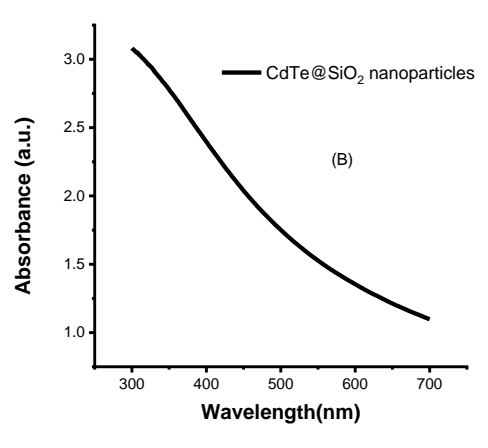

Fig.3B. Absorption spectrum of CdTe@SiO2 nanoparticles in the same condition of measurement with that of CdTe quantum dots.

\subsection{Effects of APTES Electric Neutralizer}

Firstly, we prepare silica-coated $\mathrm{CdTe} / \mathrm{ZnS}$ quantum dots, but in coating silica process APTES is not used (non APTES CdTe/SiO 2 ). Figure 4 shows a comparison of the fluorescence spectra of $\mathrm{CdTe} / \mathrm{ZnS}$ quantum dots and that of silica-coated quantum dots non APTES.

Figure 4 presents the fluorescence spectra of CdTe quantum dots and non APTES CdTe@ $\mathrm{SiO}_{2}$ nanoparticles solutions with the same concentration of quantum dots. The shape of fluorescence spectra of $\mathrm{CdTe} @ \mathrm{SiO}_{2}$ nanoparticles is similar to that of uncoated CdTe quantum dots. But fluorescence intensity of $\mathrm{CdTe} @ \mathrm{SiO}_{2}$ greatly decreased. This is explained that without the neutralizing agent, $\mathrm{SiO}_{2}$ cannot form a shell on the surface of quantum dots, while TEOS hydrolysis using $\mathrm{NaOH}$ catalyst can damage the surface of quantum dots [27] and cause reduce fluorescence of the samples. Thus, to coat silica for quantum dots, the use a neutralizing agent is needed.

Figure 5 shows fluorescence spectra of $\mathrm{CdTe} @ \mathrm{SiO}_{2}$ using various amounts of APTES. It can see that, the appearances of fluorescence spectra of $\mathrm{CdTe} @ \mathrm{SiO}_{2}$ nanoparticles prepared with diffrent APTES amounts are almost unchanged compared to that of uncoated CdTe quantum dots. But there is significant 
difference in emission intensity of $\mathrm{CdTe} @ \mathrm{SiO}_{2}$ nanoparticles samples prepared with and without APTES. When APTES was used in during the silica coating reaction, the resulted $\mathrm{CdTe} @ \mathrm{SiO}_{2}$ samples have a much greater fluorescence intensity than that of non APTES CdTe@ $\mathrm{SiO}_{2}$. This shows the role of a neutralizer in the coating of silica for quantum dots. The APTES helps silica shells growing on the surface of the quantum dots. When coated with silica shell, quantum dots become more stable, their surface is not damaged, the emission efficiency increases. In our experiment, with 3 samples using APTES amounts of 1,5; 3 and 4,5 $\mu$ l, the sample using $3 \mu \mathrm{l}$ has the highest fluorescence intensity. Samples with lower $(1,5 \mu \mathrm{l})$ and higher $(4,5 \mu \mathrm{l})$ APTES amounts give lower fluorescence intensity. Following this result, we choose neutralizing agent APTES amount of $3 \mu l$ for the next experiments.

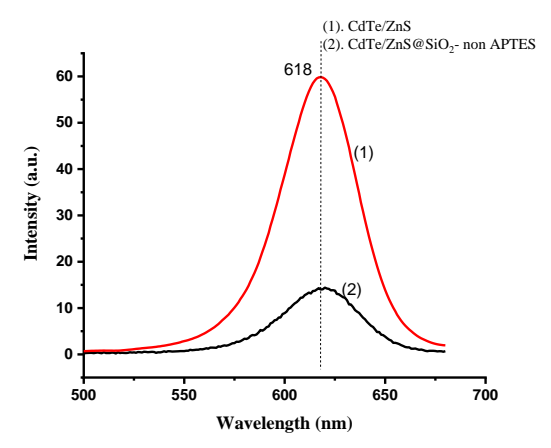

Fig 4. Comparison of fluorescence spectra of quantum dots $\mathrm{CdTe} / \mathrm{ZnS}$ and $\mathrm{CdTe} @ \mathrm{SiO} 2$ non APTES

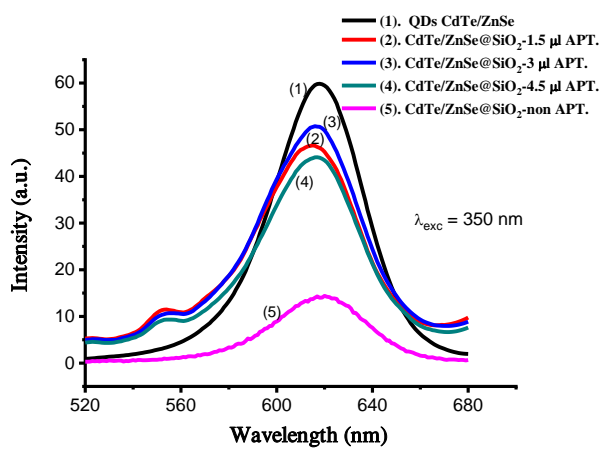

Fig 5. Fluorescence spectra of $\mathrm{CdTe} @ \mathrm{SiO}_{2}$ with various amounts of APTES

\subsection{Effects of $\mathrm{NH}_{4} \mathrm{OH}$ Amount}

In the Stöber method, the amount of $\mathrm{NH}_{4} \mathrm{OH}$ catalyst plays an important role for the granulation process, it both provides water for the hydrolysis reaction and creates a high $\mathrm{pH}$ environment to promote condensation. To investigate the effect of the amount of catalyst on the formation and optical properties of silica nanoparticles containing quantum dots, we fabricated samples with diffrent catalyst amounts. The amounts of other substances is given in Table 2.

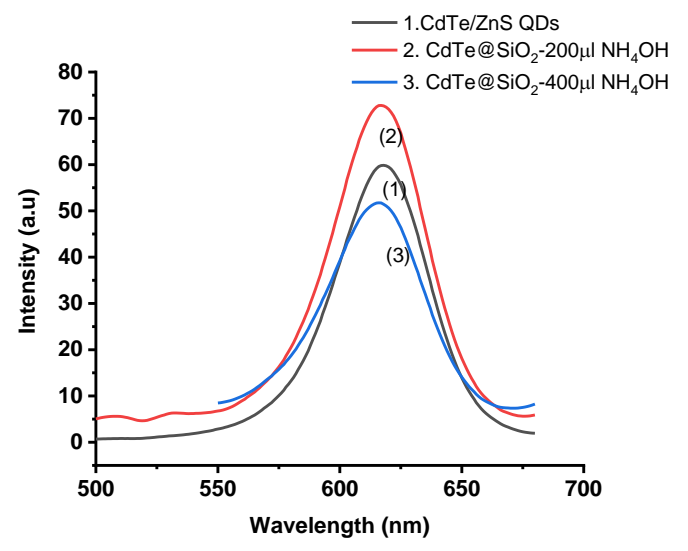

Fig 6. Comparison of fluorescence spectra of CdTe @ SiO2 nanoparticles with catalyst content of 200 and 400 $\mu 1$ versus the fluorescence spectra of uncoated $\mathrm{CdTe} / \mathrm{ZnS}$ quantum dots. 
Fig. 6 shows the comparison of fluorescence spectra of CdTe@SiO2 nanoparticles with catalyst content of 200 and $400 \mu \mathrm{l}$ versus the fluorescence spectra of uncoated CdTe/ZnS quantum dots. It can see that fluorescence intensity of $200 \mu$-catalyzed CdTe@ $@ \mathrm{SiO}_{2}$ sample is stronger than that of uncoated silica quantum dots. In our opinion, with a small amount of catalyst, hydrolysis reaction is incomplete, CdTe dots are coated with siO2, but the shell is thin, protected by thin shell quantum dots have strong emission. This result on fluorescence spectra of CdTe@ $\mathrm{SiO}_{2}$ nanoparticles is worth noting because the emission intensity is mostly lower comparing with uncoated CdTe quantum dots. But TEM immages of CdTe@ $\mathrm{SiO}_{2}$ nanoparticles (Fig.7) reveal that at $\mathrm{NH}_{4} \mathrm{OH}$ amount of $200 \mu \mathrm{l}$ (fig.7a) the particles do not have good dispersion, the sample has many small particles and there is clustering phenomenon, creating large particles. This can be explained that, at the little amount of $\mathrm{NH}_{4} \mathrm{OH}$ catalyst, it is not enough for a complete hydrolysis reaction. At higher catalysts amount $(400 \mu \mathrm{l})$, the samples have good dispersion, the particles are spherical and uniform in size (Fig. $7 b)$.
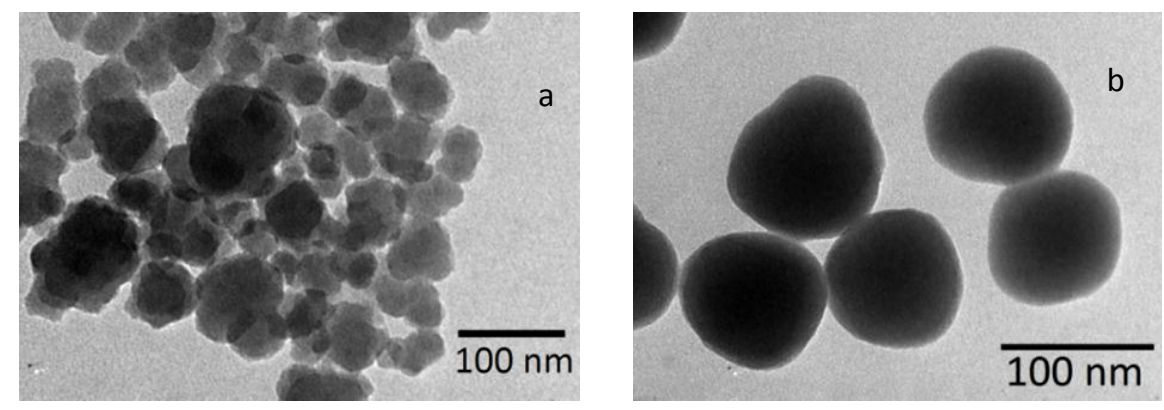

Fig.7. TEM image of $\mathrm{CdTe} @ \mathrm{SiO}_{2}$ nanoparticles with $200 \mu \mathrm{l}$ (a) and $400 \mu \mathrm{l}$ (b) $\mathrm{NH}_{4} \mathrm{OH}$.

Following this result, amounts of $\mathrm{NH} 4 \mathrm{OH}$ catalyst in our experiments have to be of $400 \mu \mathrm{l}$ or more.

Fig.8 depicts fluorescence spectra of CdTe @ $\mathrm{SiO} 2$ nanoparticles with different amounts of catalys. The fluorescence intensity of $\mathrm{CdTe} @ \mathrm{SiO}_{2}$ samples all decreased compared to that of the uncoated

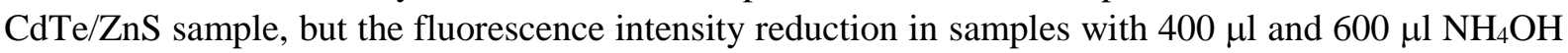
are not significant.

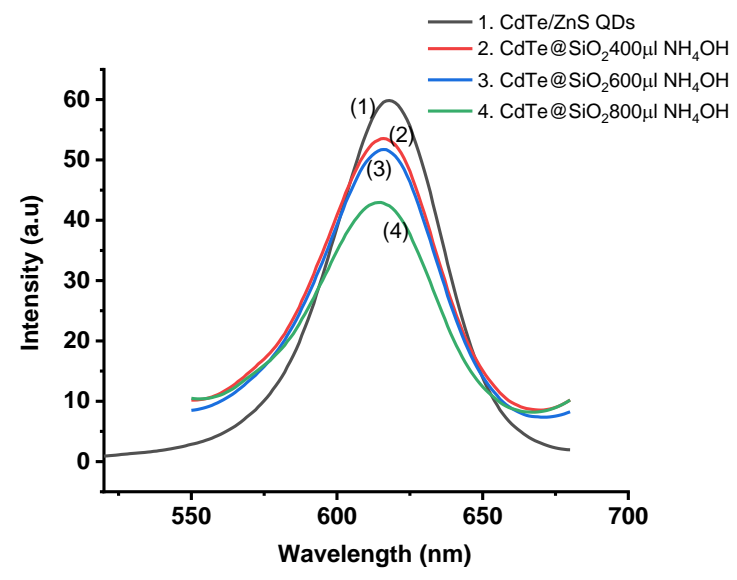

Fig.8. Fluorescence spectra of CdTe @ SiO2 nanoparticles with different amounts of catalyst. 
The fluorescence intensity of the sample decreases with increasing amount of the catalyst. This result is believed to be the initial CdTe quantum dots without silica coating, dispersed well in distilled water with a $\mathrm{pH}$ of 5.0 to 7 , when increasing $\mathrm{NH}_{4} \mathrm{OH}$ catalyst amount, the $\mathrm{pH}$ of the medium increases, influences to the emission of quantum dots. Following this result, $\mathrm{NH}_{4} \mathrm{OH}$ catalyst in our experiments has amount of $400 \mu \mathrm{l}$ or higher. Therefore, silica nanoparticles formed are spherical, uniformly size and fairly dispersed. So the in order to prepare samples with the best fluorescence, the amount of catalyst is an important factor. In our experiment, the catalyst amount of $400 \mu \mathrm{l}$ is optimal, which corresponds to the molar ratio of NH4OH: TEOS to 2.6. This result is close to the report of Yoshio Kobayashi [26].

\subsection{Effects of water amount}

The total amount of water in the silica hydrolysis reaction affects the size and the number of formed particles. When water amount in hydrolysis reaction changes, the shape, size, and the dispersion of CdTe@SiO2 nanoparticles also diversed. The amounts of other substances is given in Table 3.

Fig.9 shows TEM images of CdTe @ SiO2 nanoparticles with different water content. The H2O amount of $300 \mu \mathrm{l}$ is not enough for the hydrolysis reaction to totally occur, the $\mathrm{SiO} 2$ particles have not been formed but only form clusters of different sizes. The increase of water amount promotes the hydrolysis reaction, the number of $\mathrm{Si}$ molecules $\mathrm{Si}(\mathrm{OC} 2 \mathrm{H} 5)_{4-\mathrm{x}}(\mathrm{OH})_{\mathrm{x}}$ increases rapidly until a saturation value is reached. At $500 \mu 1$ of water, the particles are relatively formed, but the particles are still not completely spherical, not very well dispersed and have a clustering phenomenon. With $700 \mu 1$ of water, the desired particle sizes can be controlled by amount of water in the reaction.

The fluorescence spectrum of CdTe@SiO2 nanoparticles (fig.10) reveal that the photoluminescent intensity of the samples tends to decrease as the amount of water increased, except for water amount of $300 \mu$ l. Increasing of water amount corresponds to increasing of $\mathrm{SiO}_{2}$ particle size. The silica particle size increases corresponding to the thickness of the silica shell surrounding $\mathrm{CdTe} / \mathrm{ZnS}$ quantum dot being thicker. The thick $\mathrm{SiO}_{2}$ layer is cause a deterioration in the optical properties of the quantum dots,

the emission of quantum dots is obstructed by a thick silica shell. At $500 \mu \mathrm{H}_{2} \mathrm{O}$, the water amount is enough for the hydrolysis reaction, so silica particles have formed, quantum dots are protected by the silica shell, that prevent the influence of the solution environment to quantum dots, resulting in increased their fluorescences. With less water $(300 \mu \mathrm{l})$, the silica particles do not form, leading to quantum dots are affected by the environment, resulting in lower intensity fluorescence emission.
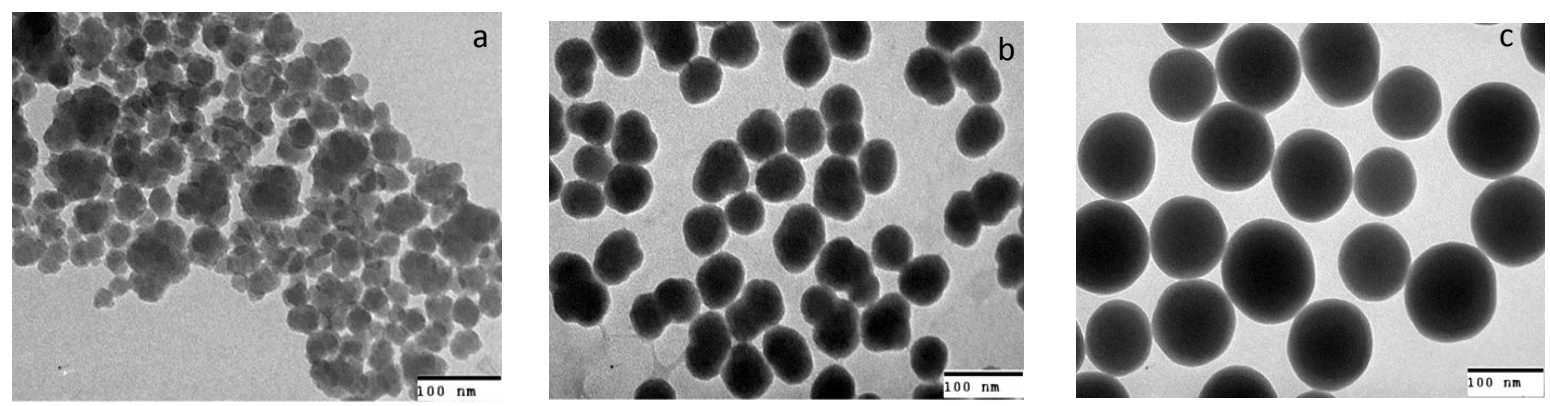

Fig.9. TEM images of CdTe @ SiO2 nanoparticles with different water content: $300 \mu 1$ (a), $500 \mu \mathrm{l}$ (b) and $700 \mu \mathrm{l}$ (c). 


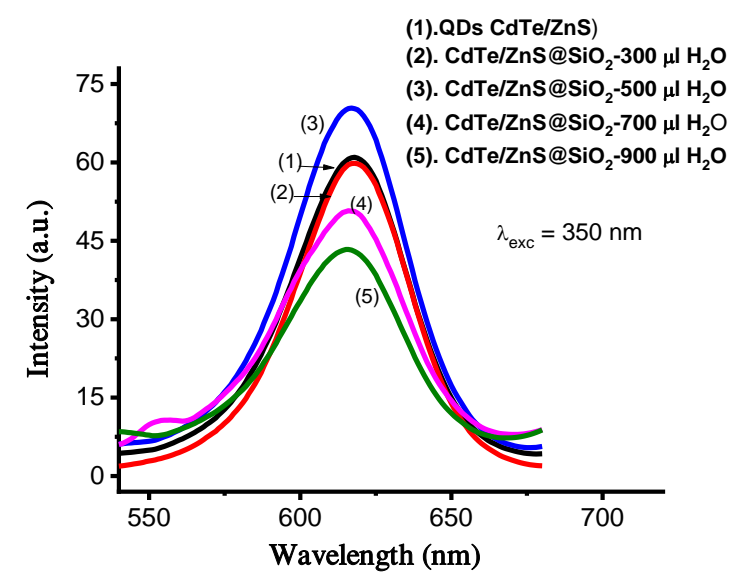

Fig.10. Fluorescence spectrum of CdTe@SiO2 nanoparticles made with different amounts of water.

In summary, using the Stöber method to coat quantum dots by silica shell, the amount of water and the amount of other substances involved in the reaction plays an important role in the formation of single dispersed particles as well as optical properties of silica nanoparticles containing quantum dots. In our experiment, the ratio of amount reaction participants ethanol: TEOS:solution of QDs: $\mathrm{NH}_{4} \mathrm{OH}$ :APTES $: \mathrm{H}_{2} \mathrm{O}$ which to formation samples with uniformly sized particles, good dispersion and fluorescence being stronger than that of uncoated quantum dots was $1.5: 1.5 \times 10^{-2}: 0.8 \times 10^{-2}: 4 \times 10^{-2}: 3 \times 10^{-4}: 5 \times 10^{-2}$ by volume.

\section{Conclusion}

The $\mathrm{SiO}_{2}$ nanoparticles containing $\mathrm{CdTe} / \mathrm{ZnS}$ quantum dots $\left(\mathrm{CdTe} @ \mathrm{SiO}_{2}\right)$ have been synthesized successfully via Stöber method. By detailed investigating manufacturing process we fuond the ratio of substances involved in the reaction to preperate silica nanoparticles containing quantum dots of $\mathrm{CdTe} / \mathrm{ZnS}$ of good quality. The $\mathrm{CdTe} @ \mathrm{SiO}_{2}$ nanoparticles have good emission, mono-dispertion, and good stability in solution. Fluorescence being stronger than that of uncoated quantum dots, this result is worth noting because the emission intensities were mostly lower comparing with that of uncoated CdTe quantum dots. This indicates that the prepared $\mathrm{CdTe} @ \mathrm{SiO}_{2}$ nanoparticles are suitable for bioapplications.

\section{Acknowledgments}

This work is supported by Vietnam National Foundation for Science and Technology Development (NAFOSTED) under grant number 103.02-2016.39.

\section{References}

[1] Wolfgang J Parak, Teresa Pellegrino, Christian Plank, Labelling of cells with quantum dots, Nanotechno- logy 16 (2005), R9-R25, https://doi.org/10.1088/0957-4484/16/2/R01.

[2] Xiaohu Gao, Lily Yang, John A Petros, Fray F Marshall, Jonathan W Simons and Shuming Nie, In vivo molecular and cellular imaging with quantum dots, Current Opinion in Biotech, 16 (2005) 63-72. https://doi.org/10.1016/j.copbio. 2004.11.003

[3] Aihua Fu, Weiwei Gu, Benjamin Boussert, Kristie Koski, Daniele Gerion, Liberato Manna, Mark Le Gros, Carolyn Larabell and A. Paul Alivisatos, Semiconductor Quantum Rods as Single Molecule Fluorescent Biological LabelsNano Lett. 7(1) (2007) 179-182. https://doi.org/10.1021/n10626434 
[4] Mark Howarth, Keizo Takao,Yasunori Hayashi, Alice Y. Ting, Targeting quantum dots to surface proteins in living cells with biotin ligase, PNAS 102 (21) (2005) 7583-7588, https://doi.org/10.1073/pnas.0503125102.

[5] M. Dahan, S. Levi, C. Luccardini, P. Rostaing, B. Riveau, A. Triller, Diffusion dynamics of glycine receptors revealed by single-quantum dot tracking, Science 302 (2003) 442-445. https://doi.org/10.1126/science.1088525

[6] X. Michalet; F.F. Pinaud; L.A. Bentolila; J.M. Tsay, S. Doose, J.J. Li, G. Sundaresan, A.M. Wu; S.S. Gambhir S. Weiss, Quantum Dots for Live Cells, in Vivo Imaging, and Diagnostics, Science 307 (2005) 538-544. https://doi.org/10.1126/science.1104274.

[7] Ung Thi Dieu Thuy, Pham Song Toan, Tran Thi Kim Chi, Dinh Duy Khang, Nguyen Quang Liem, CdTe quantum dots for an application in the life sciences, Adv. Nat. Sci.: Nanosci. Nanotechnol.1(2010) 045009 (5pp). https://doi.org/10.1088/2043-6262/1/4/045009.

[8] Thi Dieu Thuy Ung, Thi Kim Chi Tran, Thu Nga Pham, Duc Nghia Nguyen, Duy Khang Dinh, Quang Liem Nguyen, CdTe and CdSe quantum dots: synthesis, characterizations and applications in agriculture, Adv. Nat. Sci.: Nanosci. Nanotechnol. 3 (2012) 043001 (11pp). https://doi.org/10.1088/2043-6262/3/4/043001.

[9] Jun Qian, Xin Li, Ming Wei, Xiangwei Gao, Zhengping Xu, Sailing He, Bio-molecule-conjugated fluorescent organically modified silica nanoparticles as optical probes for cancer cell imaging, Optics Express 16 (24) (C) (2008) 19568-19578. https://doi.org/10.1364/OE.16.019568

[10] Sehoon Kim, Tymish Y. Ohulchanskyy, Haridas E. Pudavar, Ravindra K. Pandey, Paras N. Prasad, Organically Modified Silica Nanoparticles Co-encapsulating Photosensitizing Drug and Aggregation-Enhanced Two-Photon Absorbing Fluorescent Dye Aggregates for Two-Photon Photodynamic Therapy, J Am Chem Soc. 129(9) (2007) 2669-2675. https://doi.org/10.1021/ja0680257.

[11] A. Burns, H. Ow, U. Wiesner, Fluorescent core-shell silicanano particles: towards "Lab on a Particle" architectures for nanobiotechnology, Chem. Soc. Rev., 35 (2006) 1028-1042. https://doi.org/10.1039/b600 562b

[12] M.J. Murcia, C.A. Naumann, Biofunctionalization of Nanomaterials, Nanotechnologies for the Life Sciences, Vol. 1, WILEY-VCH Verlag GmbH \& Co. KGaA, Weinheim (2005) ISBN: 3-527-31381-8

[13] A. van Blaaderen, A. Vrij, Synthesis and Characterization of Colloidal Monodisperse Organo - Silica Spheres, J. Colloid Interface Sci., 156 (1) (1993). .https://doi.org/10.1006/jcis.1993. 1073

[14] T.I. Suratwala, M.L. Hanna, E.L. Miller, P.K. Whitman, I.M. Thomas, P.R. Ehrmann, R.S. Maxwell, A.K. Burnham, Surface chemistry and trimethylsilyl functionalization of Stöber silica sols, J. Non-Cryst. Solids, 316 (2003) 349-363. ISSN: 0022-3039

[15] Francesca Pietra, Relinde J.A. van Dijk - Moes, Xiaoxing Ke, Sara Bals, Gustaaf Van Tendeloo, Celso de Mello Donega, and Daniel Vanmaekelbergh, Synthesis of Highly Luminescent Silica-Coated CdSe/CdS Nanorods, Chem. Mater, 25 (17) (2013) 3427-3434, https://doi.org/10.1021/cm401169t.

[16] X. Gao, J. He, L. Deng, H. Cao, Synthesis and characterization of functionalized rhodamine B - doped silica nanoparticles, Optical Materials, Science Direct, (2009), Vol. 31, 1715-1719. DOI: 10.1016/j.optmat.2008.05.005

[17] H. Jeon, C. Yoon, S. Lee, D.C. Lee, K. Shin and K. Lee, Quantum efficiency of colloidal suspensions containing quantum dot/silica hybrid particles, Nanotechnology 27(43) (2016) 435702. https://doi.org/10.1088/09574484/27/43/435702.

[18] R. Koole, M.M. van Schooneveld, J. Hilhorst, C. de Mello Donegá, D.C. Hart, A. van Blaaderen, D. Vanmaekelbergh, A. Meijerink, On the inco- rporation mechanism of hydrophobic quantum dots in silica spheres by a reverse microemulsion method, Chem. Mater. 20 (2008) 2503-12. https://doi.org/10.1021/cm703348y.

[19] Nianfang Wang, Sungjun Koh, Byeong Guk Jeong, Dongkyu Lee, Whi Dong Kim, Kyoungwon Park, Min Ki Nam, Kangha Lee, Yewon Kim, Baek-Hee Lee, Kangtaek Lee, Wan Ki Bae and Doh C Lee, Highly luminescent silica-coated $\mathrm{CdS} / \mathrm{CdSe} / \mathrm{CdS}$ nanop- articles with strong chemical robustness and excellent thermal stability”, J. Nanotechnology Volume 28, Number 18 (2017) 185603 (8pp). https://orcid.org/0000-0002-3489-6189

[20] Rumiana Bakalova, Zhivko Zhelev, Ichio Aoki, Hideki Ohba, Yusuke Imai, Iwao Kanno, Silica-Shelled Single Quantum Dot Micelles as Imaging Probes with Dual or Multimodality, Anal. Chem. 78 (16) (2006) 5925-5932, https://doi.org/10.1021/ ac060412b.

[21] Yunhua Yang, Mingyan Gao, Preparation of Fluorescent SiO2 Particles with Single CdTe Nanocrystal Cores by the Reverse Microemulsion Method, Adv.Mater 17 (2005) 2354-2357. https://doi.org/10.1002/ adma.200500403.

[22] T. Nann, P. Mulvaney, Single quantum dots in spherical silica particles, Angew. Chem. Int. Ed. 43(2004) 53935396. https://doi.org/10.1002/anie.200460752. 
[23] Masih Darbandi, Ralf Thomann, Thomas Nann, Single Quantum Dots in Silica Spheres by Microemulsion Synthesis, Chem. Mater. 17 (2005) 5720-5725. https://doi.org/10.1021/cm 051467h.

[24] Chao Wang, Qiang Ma,Wenchao Dou, Shamsa Kanwal, GuannanWang, Pingfan Yuan, Xingguang Su, Synthesis of aqueous CdTe quantum dots embedded silica nanoparticles and their applications as fluorescence probes, Talanta 77 (4) (2009) 1358-1364. ISSN: 0039 - 9140.

[25] Yoshio Kobayashi, Takuya Nozawa, Tomohiko Nakagawa, Kohsuke Gonda, Motohiro Takeda, Noriaki Ohuchi, Atsuo Kasuya, Direct coating of quantum dots with silica shell, J Sol-Gel Sci Technol. 55 (2010) 79-85. https://doi.org/ 10.1007/s10971-010-2218-5.

[26] D.A.H. Hanaor, M. Michelazzi, C. Leonelli, C. C. Sorrell, The effects of carboxylic acids on the aqueous dispersion and electrophoretic deposition of $\mathrm{ZrO} 2$, Journal of the European Ceramic Society 32 (1) (2012) 235-244. https://doi.org/ 10.1016/j.jeurceramsoc.2011.08.015

[27] Ning Liu and Ping Yang, Highly luminescent hybrid SiO2-coated CdTe quantum dots: synthesis and properties, J.Luminescence 28 (2013) 542-5. https://doi.org/10.1002/bio.2491. 